Research Article

\title{
Dynamic Properties of Clean Sand Modified with Granulated Rubber
}

\author{
Dervis Volkan Okur $\mathbb{D D}^{1}$ and Seyfettin Umut Umu ${ }^{2}$ \\ ${ }^{1}$ Department of Civil Engineering, Eskişehir Osmangazi University, Eskişehir, Turkey \\ ${ }^{2}$ Vocational School of Transportation, Anadolu University, Eskişehir, Turkey \\ Correspondence should be addressed to Dervis Volkan Okur; vokur@ogu.edu.tr
}

Received 20 November 2017; Revised 20 April 2018; Accepted 2 May 2018; Published 27 May 2018

Academic Editor: Dimitris Rizos

Copyright ( 2018 Dervis Volkan Okur and Seyfettin Umut Umu. This is an open access article distributed under the Creative Commons Attribution License, which permits unrestricted use, distribution, and reproduction in any medium, provided the original work is properly cited.

\begin{abstract}
Waste automobile tires are used as additives or replacements instead of traditional materials in civil engineering works. In geotechnical engineering, tires are shredded to certain sizes and mixed with soil, especially used as backfill material behind retaining walls or fill material for roadway embankments. Compared to soil, rubber has high damping capacity and low shear modulus. Therefore, it requires the determination of the dynamic characteristics of rubber/soil mixtures. In this paper, the cyclic behavior of recycled tire rubber and clean sand was studied, considering the effects of the amount and particle size of the rubber and confining stresses. A total of 40 stress-controlled tests were performed on an integrated resonant column and dynamic torsional shear system. The effects of the relative size and proportion of the rubber on the dynamic characteristics of the mixtures are discussed. The dynamic properties, such as the maximum shear modulus, strain-dependent shear modulus, and damping ratio, are examined. For practical purposes, simple empirical relationships were formulated to estimate the maximum shear modulus and the damping ratio. The change in the shear modulus and damping ratio with respect to shear strain with $5 \%$ of rubber within the mixture was found to be close to the behavior of clean sand.
\end{abstract}

\section{Introduction}

In civil engineering practice, the use of automobile tire waste has gained wide popularity in various applications in the last three decades. It is used as additives or replacements for conventional materials in construction work. Regulations such as ASTM D6720-98 have standardized the use of waste tire for the classification [1]. Standardization of waste tire is done according to the disintegration method and the size of the disintegrated product during the recycling process. Waste automobile tires are generally cut up into small pieces of different sizes and mixed with structural materials in some predetermined proportions in order to achieve the desired engineering properties. In transportation engineering, waste tires have been used as asphalt binder modifiers and asphalt mixture additives in gap-graded or open-graded asphalt mixtures and surface treatments. Also, it has been reported that adding recycled tire to asphalt provides increased rutting resistance, friction resistance, ride quality, extended pavement life, and reduced noise and vibration levels $[2,3]$.
Due to the low cost of application, waste tires are preferred in geotechnical engineering projects as well. After some shredding processes, they can be used alone, embedded, or mixed with soils. The geotechnical use of waste tire-soil mixtures is mainly preferred within transportation infrastructures or in vibration damping systems to reduce vibrations, such as on railroad subgrades or machine foundations. Other geotechnical applications have been reported as embankment fills, retaining walls and bridge abutment backfills, insulation layers to limit frost penetration, and drainage layers. Sometimes whole tires are used as retaining walls or reinforcement layers in an earth-fill or floating breakwater [4-6].

Extensive studies on the behavior of recycled tire/soil mixtures have been conducted over the last few decades. These studies are usually based on the evaluation of conventional engineering properties such as compaction characteristics, permeability, and shear strength parameters where the tire/soil mixtures are mostly considered under static loading conditions. Investigations of the dynamic 


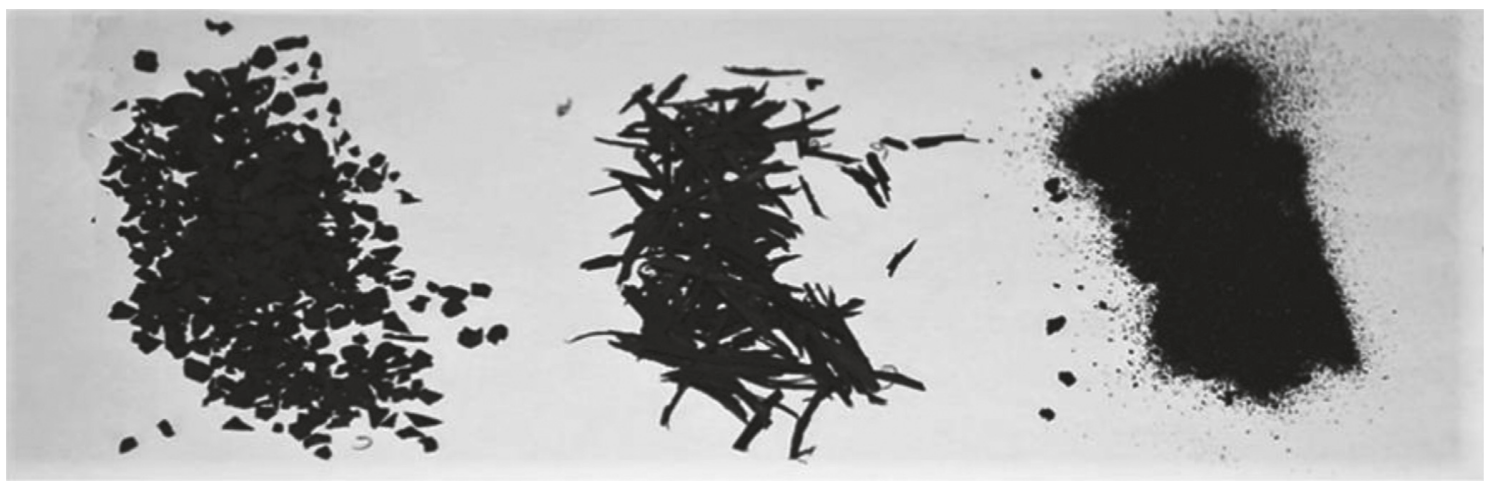

Figure 1: Granular rubber material used in the study.

characteristics of recycled tire/soil mixtures are rather limited and new.

Hazarika [7] conducted shake table tests on tire chips and sand mixtures to investigate liquefaction resistance. Hyodo et al. [8], Senetakis et al. [9, 10], and Anastasiadis et al. [11] gave some perspectives on the dynamic properties of granulated rubber/sand mixtures. Senetakis et al. [12] and Anastasiadis et al. [13] proposed some empirical relationships regarding the dynamic characteristics of rubber/soil mixtures.

In terms of physical properties, tire rubber structure is quite different from the soil fabric. The damping capacity of tire rubber is much higher because of its high elasticity as compared to soil. Therefore, tire rubber exhibits much more elastic deformation than the soil. Its stress-strain curve is almost reversible when the stress is released, and its Young's modulus and shear strength are extremely low as compared to soil. The presence of such differences in their physical properties makes the behavior of the new composite material quite complicated. Therefore, understanding the behavior of recycled tire-soil mixtures under cyclic loads is essential in determining the factors and parameters to be used in the design.

The purpose of this work was to understand the controlling factors responsible for the dynamic behavior of recycled tire/soil mixtures of varying proportions by conducting cyclic tests under different cyclic shear amplitudes. The variations of the dynamic soil parameters, such as maximum shear modulus (the value of the shear modulus at a very small strain, $\left.\gamma \approx 5 \times 10^{-4} \%\right)$, strain-dependent shear modulus, and damping ratio, were investigated. The effects of the particle size and the amount of recycled tire in the mixtures were also examined. The test results were compared with similar studies in the literature. For reference purposes, some relationships are also proposed regarding the shear modulus and the damping ratio.

\section{Materials and Methods}

The synthetic material used in the study was "waste tire," but for convenience, it will be referred to as "rubber" henceforth. Chipped rubber obtained from recycled tires was processed through a series of mechanical shredding operations. After the grinding process, the material was sieved and separated into three different uniform sizes. The specific gravity of the pure crumb rubber (free from fabric and wire) was calculated using the ASTM D854 [14], specification as $G_{S}=1.11$. It is important to note that the thermal expansion capacity of the crumb rubber was much higher than that of the soil grains; therefore, specific gravity can vary depending on the ambient temperature. Typical results from studies reported the specific gravity of crumb rubber between 1.00 and 1.30 depending on the amount of contamination or fabric content [15-17]. The chipped rubber particles were coded according to their sizes as R\#1 fraction between \#3/8 and 4 sieve, R\#2 fraction between \#4 and 10 sieve, and $\mathrm{R} \# 3$ fraction under \#100 sieve (Figure 1).

For the soil material, standard clean sand was used. The mean diameter of the quartz-rich sand is $D_{50}=0.53 \mathrm{~mm}$, uniformity coefficient of $C_{\mathrm{U}}=6.3, G_{\mathrm{S}}=2.68, e_{\max }=0.88$, and $e_{\min }=0.55$. Poisson's ratio of rubber is almost 0.5 , meaning volumetric compressibility is almost zero and rubber solids can be assumed to be incompressible. The grain size distribution curves of the rubber samples and the sand are shown in Figure 2.

The samples were prepared by mixing the chipped tire and sand at different weight ratios. It was reported that the structural matrix created by different techniques of sample preparation could change the cyclic response of sandy soils [18]. Hence, if dynamic tests are to be conducted on reconstituted samples, a general routine is to outline the sample preparation technique. Since in situ applications of rubber/soil mixtures are generally constructed above groundwater level, it is apparent that a dry deposition method is considered to best reproduce field conditions. Therefore, the dry deposition technique was chosen for sample preparation. The quartz sand was dried out in an oven for 24 hours at $105^{\circ} \mathrm{C}$, and the granular rubber was left at room temperature for 36 hours. The sand and granular rubber were then mixed with a mechanical mixer for 15 minutes in order to generate as homogeneous a mixture as possible. The samples were prepared by pouring the rubber/sand into an aluminum mold $50 \mathrm{~mm}$ in diameter and $105 \mathrm{~mm}$ in height. To obtain the target densities, the samples were compacted by a wooden hammer. The initial void ratios of the samples with respect to rubber volume are given in Table 1. 


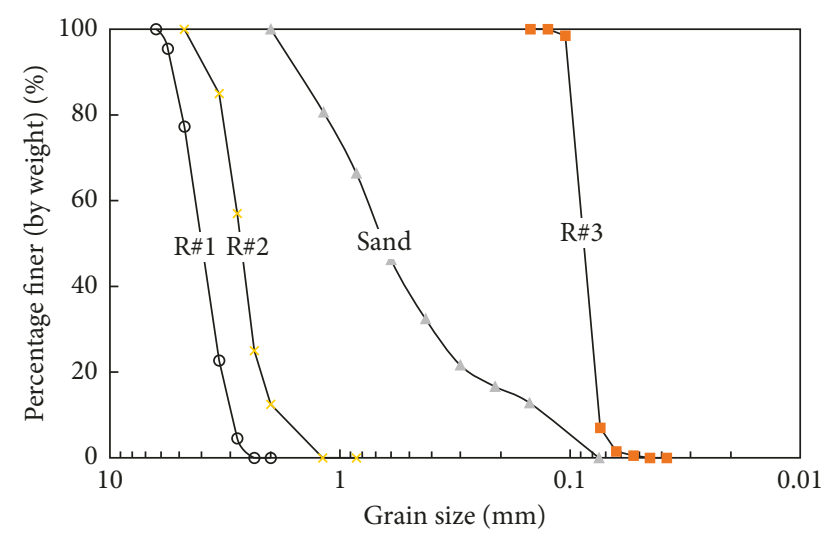

FIGURE 2: The grain size distribution curves of the rubber and sand.

TABLE 1: Summary of parameters of dynamic tests.

\begin{tabular}{|c|c|c|c|c|c|}
\hline $\begin{array}{l}\text { Test } \\
\text { series }\end{array}$ & $\begin{array}{c}\sigma_{\mathrm{o}}^{\prime} \\
(\mathrm{kPa})\end{array}$ & $\begin{array}{c}\text { Rubber } \\
\text { type }\end{array}$ & $\begin{array}{c}\text { Rubber } \\
\text { content }(\%)\end{array}$ & $\begin{array}{l}\text { Cycle number at } \\
\text { failure, } N_{f}\end{array}$ & $\begin{array}{c}G_{\max } \\
(\mathrm{MPa})\end{array}$ \\
\hline \multirow{4}{*}{$1-\mathrm{R} \# 1$} & 50 & \multirow{4}{*}{$\mathrm{R} \# 1$} & \multirow{4}{*}{5} & 230 & 43 \\
\hline & 100 & & & 360 & 91 \\
\hline & 150 & & & 410 & 120 \\
\hline & 200 & & & 440 & 152 \\
\hline \multirow{4}{*}{$2-\mathrm{R} \# 1$} & 50 & \multirow{4}{*}{$\mathrm{R} \# 1$} & \multirow{4}{*}{10} & 200 & 35 \\
\hline & 100 & & & 309 & 70 \\
\hline & 150 & & & 370 & 103 \\
\hline & 200 & & & 408 & 120 \\
\hline \multirow{4}{*}{ 3-R\#1 } & 50 & \multirow{4}{*}{$\mathrm{R} \# 1$} & \multirow{4}{*}{15} & 190 & 26 \\
\hline & 100 & & & 280 & 54 \\
\hline & 150 & & & 330 & 82 \\
\hline & 200 & & & 350 & 97 \\
\hline \multirow{4}{*}{$1-\mathrm{R} \# 2$} & 50 & \multirow{4}{*}{$\mathrm{R} \# 2$} & \multirow{4}{*}{5} & 280 & 46 \\
\hline & 100 & & & 515 & 102 \\
\hline & 150 & & & 708 & 163 \\
\hline & 200 & & & 740 & 185 \\
\hline \multirow{4}{*}{$2-\mathrm{R} \# 2$} & 50 & \multirow{4}{*}{$\mathrm{R} \# 2$} & \multirow{4}{*}{10} & 200 & 35 \\
\hline & 100 & & & 330 & 72 \\
\hline & 150 & & & 395 & 105 \\
\hline & 200 & & & 427 & 122 \\
\hline \multirow{4}{*}{$3-R \# 2$} & 50 & \multirow{4}{*}{$\mathrm{R} \# 2$} & \multirow{4}{*}{15} & 140 & 25 \\
\hline & 100 & & & 230 & 60 \\
\hline & 150 & & & 300 & 85 \\
\hline & 200 & & & 314 & 108 \\
\hline \multirow{4}{*}{$1-\mathrm{R} \# 3$} & 50 & \multirow{4}{*}{$\mathrm{R} \# 3$} & \multirow{4}{*}{5} & 230 & 65 \\
\hline & 100 & & & 349 & 125 \\
\hline & 150 & & & 410 & 171 \\
\hline & 200 & & & 431 & 193 \\
\hline \multirow{4}{*}{$2-\mathrm{R} \# 3$} & 50 & \multirow{4}{*}{$\mathrm{R} \# 3$} & \multirow{4}{*}{10} & 160 & 51 \\
\hline & 100 & & & 300 & 110 \\
\hline & 150 & & & 361 & 167 \\
\hline & 200 & & & 391 & 185 \\
\hline \multirow{4}{*}{$3-R \# 3$} & 50 & \multirow{4}{*}{$\mathrm{R} \# 3$} & & 117 & 25 \\
\hline & 100 & & & 256 & 62 \\
\hline & 150 & & 15 & 303 & 90 \\
\hline & 200 & & & 421 & 105 \\
\hline & 50 & & & 280 & 65 \\
\hline Control & 100 & & & 411 & 122 \\
\hline Control & 150 & - & - & 470 & 174 \\
\hline & 200 & & & 498 & 202 \\
\hline
\end{tabular}

The cyclic loading tests were carried out by using an integrated resonant column/cyclic torsional shear test. The resonant column (RC) test is based on the theory of the wave propagation of prismatic bars. The test data analysis followed that was described in detail by Drnevich [19] and used Standard ASTM D4015 [20].

Harmonic torsional excitation was applied to the top of the specimen by an electric motor. A torsional harmonic load with constant amplitude was applied over a range of frequencies, and the response curve (strain amplitude) was measured (Figure 3 ). The shear wave velocity was obtained by measuring the first-mode resonant frequency. The maximum shear modulus was calculated from this shear wave velocity and the soil density. Material damping obtained from the free-vibration decay after the forced vibration was stopped. After the determination of the maximum shear modulus and the minimum damping ratio, the cyclic torsional harmonic load amplitude was increased to obtain the strain-dependent shear modulus and damping values for a wide strain range $\left(10^{-4} \%-10^{0.7} \%\right)$.

\section{Results}

The hysteretic nature of the rubber materials of three different sizes is shown in Figure 4. The cyclic stress-strain behavior of the three different sizes of rubber is almost identical irrespective of the dimensions, as expected. Under cyclic loading, the deformation behavior of rubber material is purely elastic and recoverable. This trend is similar to the observed behavior of soils, which does not change with the increase of cycles if the amplitude of cyclic shear strains is on the order of $10^{-6}$. During the period of cyclic stress application in this stage, the modulus and damping characteristics stay the same. For soils, however, after a certain cyclic shear strain threshold, nonlinear hysteretic behavior is observed. This type of response is seen when the induced shear strain is within the range of $10^{-5}$ and $10^{-3}$.

In the seismic response analysis, three main essential dynamic characteristics of soil need to be evaluated. The first one is the maximum shear modulus, $G_{0}$, which can be measured in the order of $\sim 10^{-5}-10^{-3} \%$ cyclic strain range. In this strain range, the soil behavior is assumed to be elastic. The other major parameters are the shear modulus ratio, $G / G_{0}$, and the damping ratio, which are generally used in the nonlinear analysis. In the following, these characteristics will be discussed with respect to the size and amount of rubber in the mixture.

The consolidation process was performed isotropically to a preidentified effective confining stress of 50, 100, 150, and $200 \mathrm{kPa}$. In similar studies [21], the time of consolidation was suggested from $30 \mathrm{~min}$ to 1 hour (depending on the percentage of rubber) due to the possible axial compression creep of rubber. In this study, 1 hour was allowed to elapse for consolidation in each confining stress increment regardless of the rubber content. At each stage of confining stress, the maximum shear modulus and minimum damping ratio values were determined by using the resonant column test. The half power bandwidth method was used to 


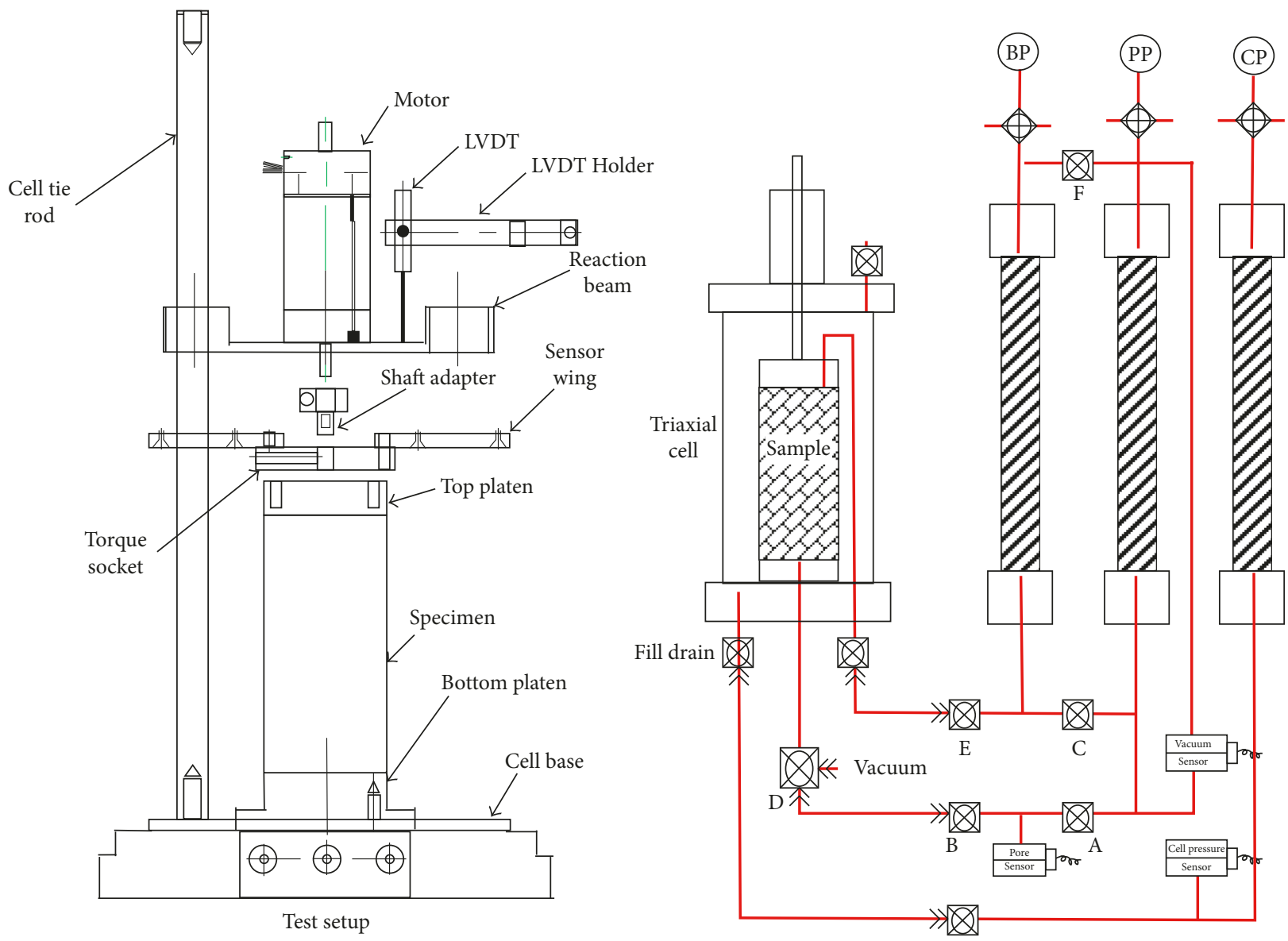

FIGURE 3: Schematic diagram of the resonant column/torsional shear system.

compute damping. Immediately after that, the torsional shear test was conducted to determine strain-dependent dynamic characteristics.

The nonlinear cyclic response of soils is generally defined by a simple relationship using the hyperbolic model [22]. Cyclic response of soils is strain dependent. In the hyperbolic model, it is assumed that the stress-strain curve of the soil is constrained between two tangent lines for small and large strains, respectively. Figure 5 illustrates these margins. From the figure, the maximum shear modulus, $G_{\max }$, is defined as the tangent line at a strain value of $\gamma<10^{-5} \%$ and the strength of soil $\tau_{\mathrm{f}}$ which represents the upper boundary is defined as the tangent line at a strain value of $\gamma>10^{-3} \%$. The stress-strain diagram between these two tangential lines can be expressed by the following equation:

$$
\frac{d \tau}{d \gamma}=G_{\max }\left(1-\frac{\tau}{\tau_{\mathrm{f}}}\right)^{n},
$$

where $n$ is chosen arbitrarily. Equation (1) can be solved by integrating for the case $n=1$; to satisfy an initial condition, $\gamma=0$ when $\tau_{\mathrm{f}}=0$ :

$$
\gamma=\frac{\gamma_{\mathrm{r}}}{n-1}\left[\frac{1}{\left(1-\left(\tau / \tau_{\mathrm{f}}\right)\right)^{n-1}}-1\right],
$$

where $\gamma_{\mathrm{r}}$ is defined as the reference strain. It is the value of strain for an elastic material at failure stress and is defined as

$$
\gamma_{\mathrm{r}}=\frac{\tau_{\mathrm{f}}}{G_{\max }} .
$$

The stress-strain curve can be calculated from (2) by placing $n=2$ as follows:

$$
\tau=\frac{G_{\max } \gamma}{1+\left(\gamma / \gamma_{\mathrm{r}}\right)} .
$$

The secant modulus can be determined as follows:

$$
\frac{G}{G_{\max }}=\frac{1}{1+\left(\gamma_{\mathrm{a}} / \gamma_{\mathrm{r}}\right)},
$$

where $\gamma_{\mathrm{a}}$ is the cyclic shear strain amplitude and $G=\tau_{\mathrm{a}} / \gamma_{\mathrm{a}}$.

The maximum shear modulus values were in the range of 60 to $200 \mathrm{MPa}$. The hyperbolic model was used to predict the strain-dependent characteristics of sand samples. The dots represent the experimental data, and the solid lines represent the numerical results (Figure 6).

As mentioned above, the deformation properties of soil under cyclic loading are greatly nonlinear after a certain threshold strain. Also, due to the elastic nature of the rubber, the exhibited cyclic deformations of rubber/soil mixtures are purely elastic and recoverable as the amount of rubber increases. This is shown by the variation of the shear modulus 


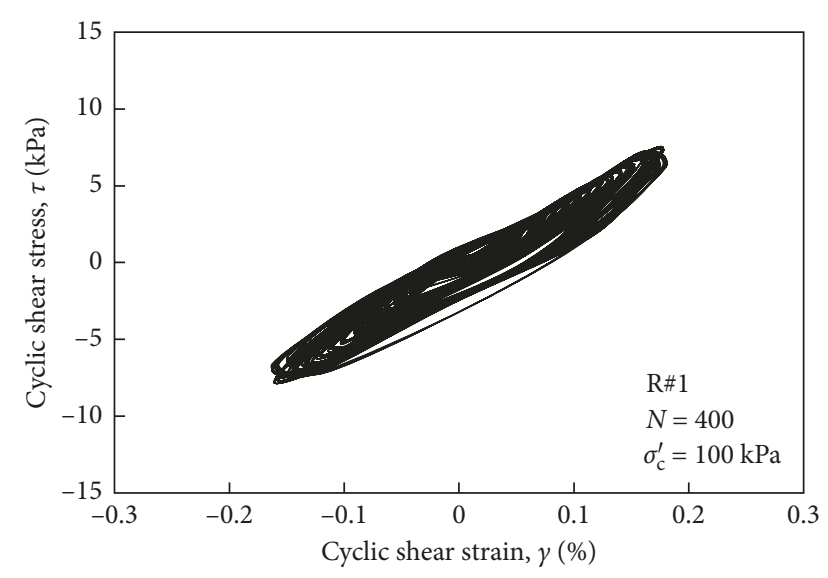

(a)

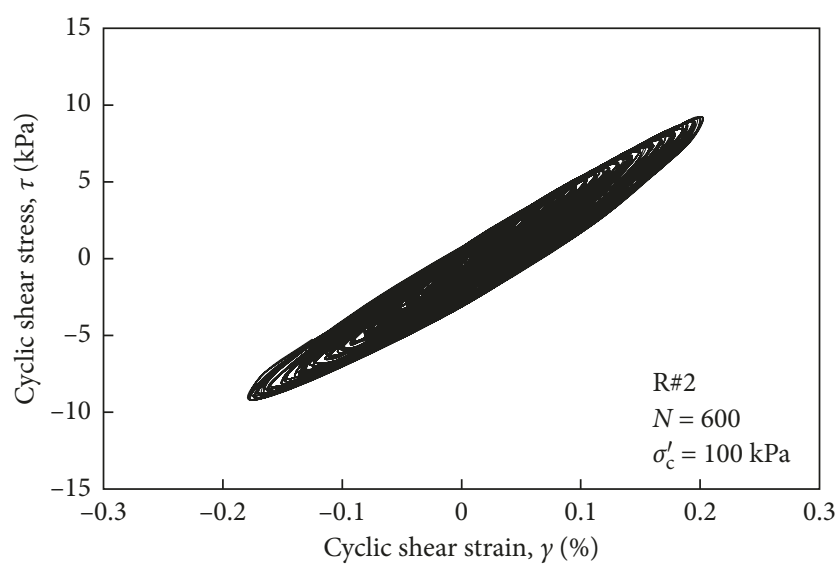

(b)

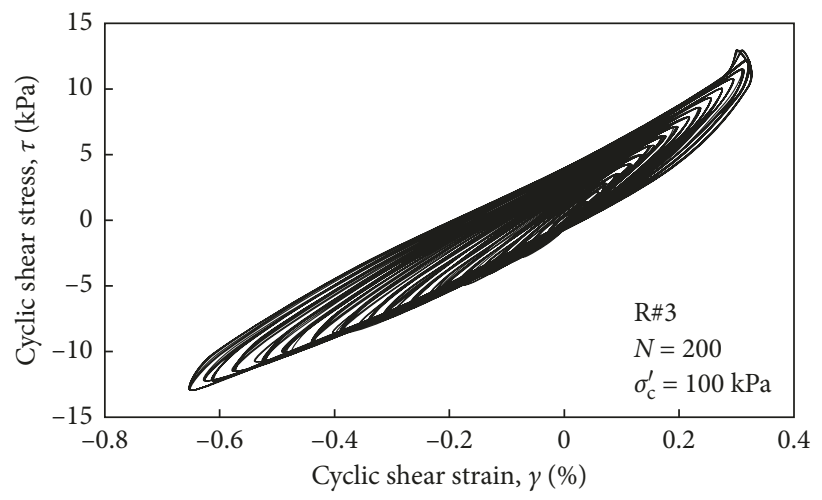

(c)

Figure 4: Typical cyclic stress-stain behavior of rubber materials used in the study.

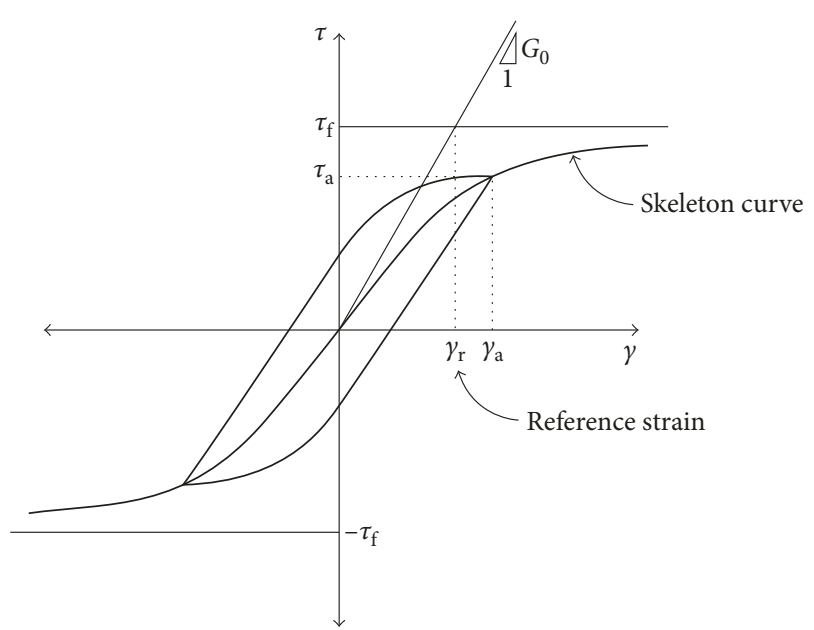

Figure 5: Definition of reference strain (adapted from [22]).

and damping ratio with respect to cyclic shear strain amplitude. In these figures, the shear modulus values normalized to the maximum shear modulus at a strain amplitude of $10^{-6}$ and plotted against the cyclic shear strain.

The results of the tests under the confining stresses of 50 , 100,150 , and $200 \mathrm{kPa}$ with the rubber proportions of $5 \%, 10 \%$, and $15 \%$ are presented in Figures $7-9$ and summarized in Table 1. To see the effects of the rubber, the results are superimposed with the results of the clean sand. The clean sand and rubber/sand mixtures are represented by the solid lines and markers, respectively. The degradation of the mixture stiffness is shown in the modulus reduction curves with the progression of cyclic strain. From the figures, it is apparent that the shape of the rubber and the effective confining pressure are the major factors affecting cyclic behavior.

As can be seen in Figure 7(a), the R\#1 mixture has a very low stiffness value compared to clean sand. For each mixture type, the degradation response of the shear modulus with increasing rubber content (for 10\% and 15\%) becomes smaller. The maximum shear modulus and secant shear modulus decrease with increasing rubber content, and confining stress decreases almost about half of the values of clean sand.

The degradation in stiffness is more significant with an increasing amount of rubber. The rubber sizes of $\mathrm{R} \# 1$ and $\mathrm{R} \# 2$ are relatively bigger; therefore, they have larger void ratios as compared to $\mathrm{R} \# 3$. The shear modulus at a given cell pressure decreases with an increase in the void ratio. For mixtures $\mathrm{R} \# 2$ and $\mathrm{R} \# 3$, the shear modulus is almost coincident with the shear modulus of clean sand over the whole strain range for the rubber content of $5 \%$. The shear modulus 


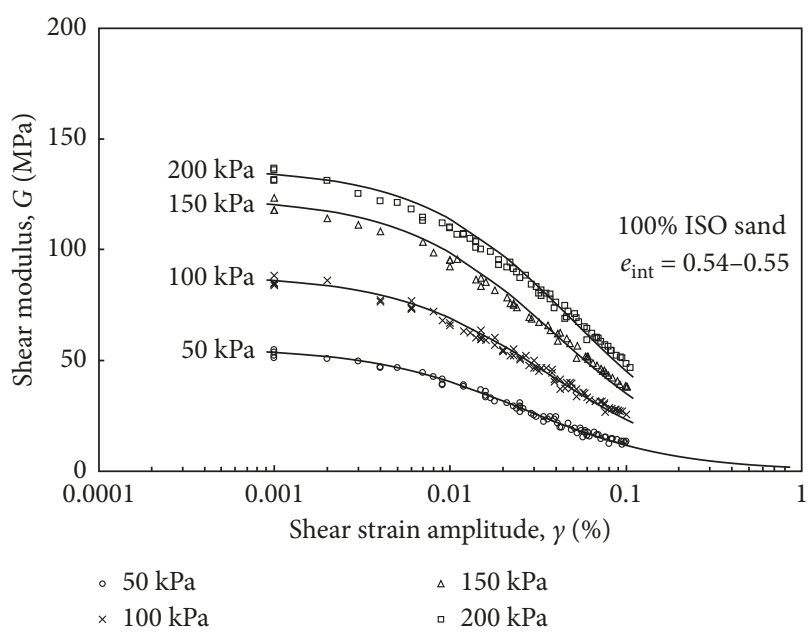

(a)

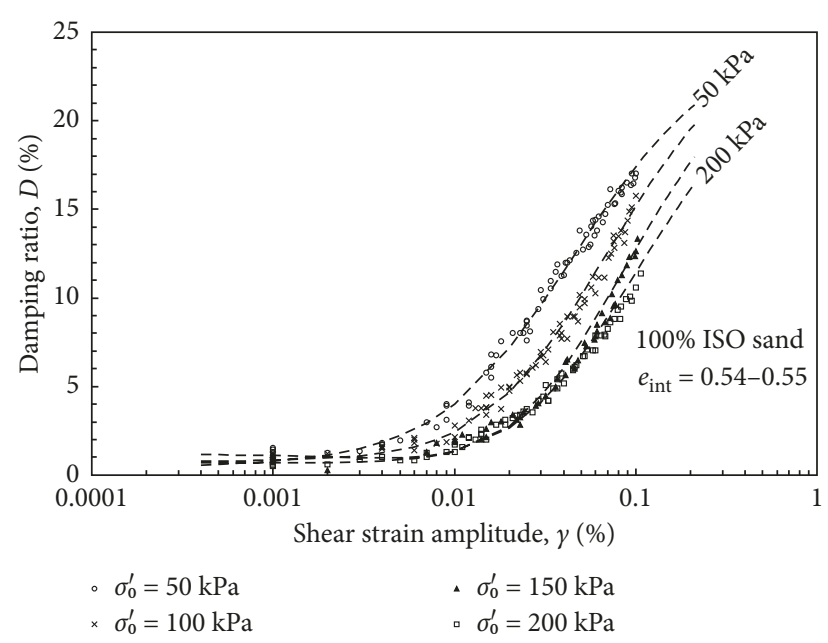

(b)

Figure 6: (a) Shear modulus versus shear strain amplitude for clean sand. (b) Damping ratio versus shear strain amplitude for clean sand.

values were also somewhat higher for both $R \# 2$ and $R \# 3$ compared to clean sand.

However, for higher rubber content, $\mathrm{R} \# 2$ and $\mathrm{R} \# 3$ show practically the same behavior as R\#1. For the confining pressures higher than $50 \mathrm{kPa}$, this fact can be attributed to the small amount of rubber particles filling the gaps between the sand particles and making the mixture denser, therefore exhibiting greater stiffness. However, a significant reduction in stiffness occurs with $10 \%$ and $15 \%$ of rubber content regardless of the size and shape of the rubber. Therefore, adding more than $5 \%$ rubber into the mixture does affect the stiffness, and the mixture then acts as if it were pure rubber. This fact can be observed in the figures that show $15 \%$ rubber content because the shear modulus ratio barely changes with the shear strain amplitude at all levels of confining stresses.

The degradation of the shear modulus with strain falls into a narrow area. Also, the decrease rate in the straindependent shear modulus is smaller in R\#1 and R\#2 compared to that in $\mathrm{R} \# 3$. This difference can be attributed to insufficient coupling between the rubber and the sand particles because of the relatively bigger size of R\#1 and R\#2, which acts like voids. On the contrary, with a considerably finer particle dimension, R\#3 seems to show more resistance to cyclic loading. This fact can be considered as the same reasoning in the reduction of the maximum shear modulus values of the rubber/sand mixtures. The damping characteristics of sand and the rubber/sand mixtures evaluated from the same test groups above are shown in Figures 7(a), $8(\mathrm{a})$, and 9(a). The R\#1 and R\#2 mixtures have lower damping ratios than clean sand for the same cyclic strain amplitude. This can be agreed as a result of the void ratio fact as explained in the previous paragraphs. Also, the variation of damping with respect to cyclic shear strain is more correlated with clean sand curves. This correlation is clear for the R\#2 and R\#3 mixtures at $100 \mathrm{kPa}$ confining stresses. The damping ratio of clean sand converges to a value of about $22 \%$ when the shear strain approaches $0.2 \%$. The same behavior can be seen with $5 \% \mathrm{R} \# 2$ and $\mathrm{R} \# 3$. The decreasing trend of the damping ratio with increasing rubber content is also seen in the figures. The damping ratio at failure strain decreases as the rubber content increases. As the confining stress increases, the reduction rate increases and converges to a value between 15 and $20 \%$. The figures also indicate that there is practically no influence of sand particles on the strain-dependent damping of mixtures with rubber content higher than $10 \%$. The damping ratio at failure strain is approximately $50 \%$ less than the corresponding damping of sand for R\#1 and R\#2. The effect of confining stress on the strain-dependent damping is negligible. However, the damping at low strains has decreased slightly as the cell pressure increases. Clean sand samples have smaller voids compared to rubber/sand mixtures. Also, the modulus of rubber is lower compared to that of sand in mixtures. For the test data, a relationship was adjusted from [12] to model the decrease rate in shear modulus cyclic strain amplitude using the hyperbolic model $[23,24]$ as

$$
\frac{G}{G_{0}}=\frac{1}{1+\left(\gamma / \gamma_{\text {ref,mix }}\right)}
$$

where $\gamma$ is the cyclic shear strain amplitude and $\gamma_{\text {ref,mix }}$ is the reference strain of the mixture for $G / G_{0}=0.5$. Presenting this condition into the equation proposed by Senetakis et al. [12], the reference strain is shown to be related as

$$
\gamma_{\text {ref,mix }}=\gamma_{\text {ref,mix, } 100} \times A_{\gamma} \times\left(\sigma_{\mathrm{m}}^{\prime}\right)^{n_{\gamma}},
$$

where $\gamma_{\text {ref,mix }}$ is the reference strain for all data sets under all confinement pressures. The constants $A_{\gamma}$ and $n_{\gamma}$ were determined by the regression analysis and are presented in Table 2. $\gamma_{\text {ref,mix,100 }}$ is the reference strain of mixtures under $100 \mathrm{kPa}$ confinement given as

$$
\gamma_{\text {ref,mix, } 100}=\gamma_{\text {ref,sand }, 100} x f\left(x_{\gamma}\right),
$$



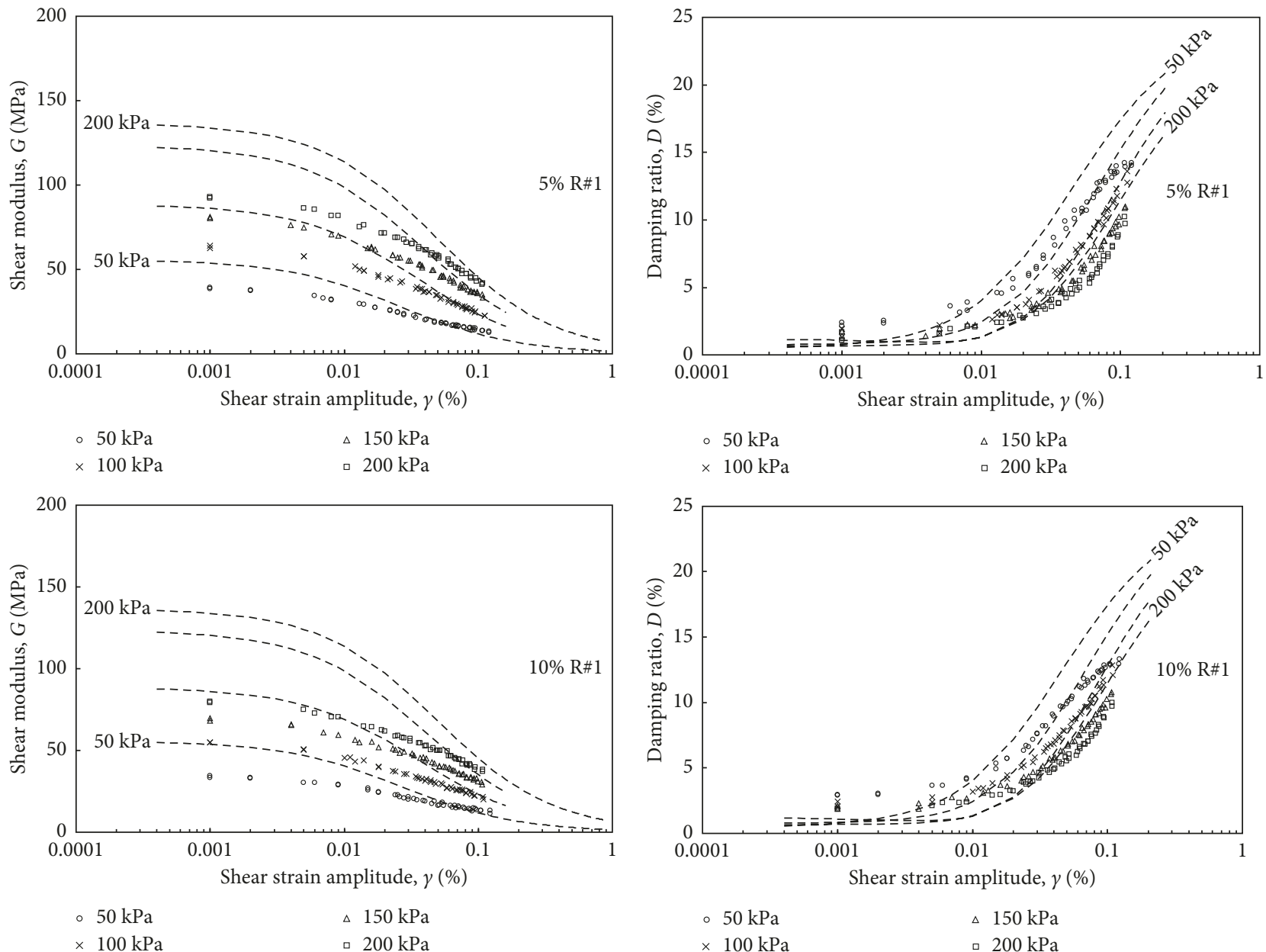

$\times 100 \mathrm{kPa} \quad$ 口 $200 \mathrm{kPa}$

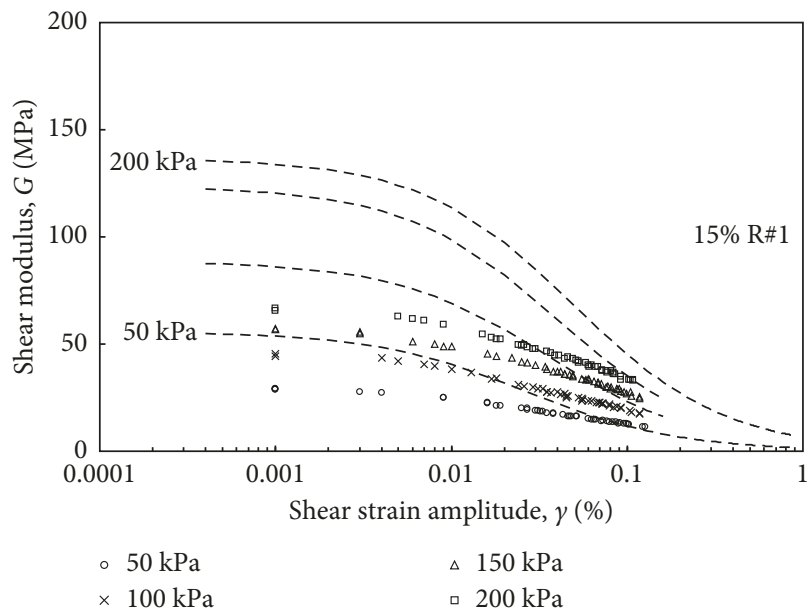

(a)

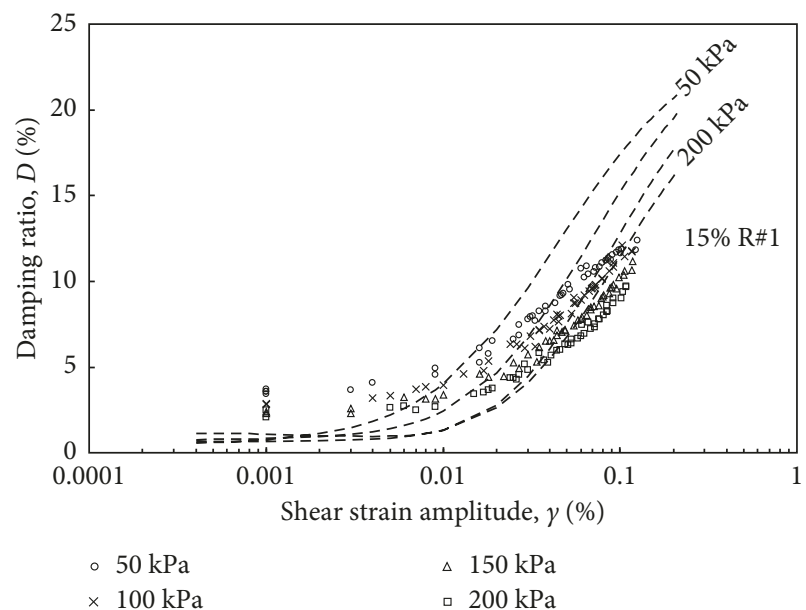

(b)

FIgURE 7: R\#1 sand mixture: (a) strain-dependent shear modulus and (b) strain-dependent damping ratio.

where $\gamma_{\text {ref,sand,100 }}$ is the reference strain defined as a function of $100 \mathrm{kPa}$ confining pressure of clean sand. The damping ratio shown as $f\left(x_{\gamma}\right)$ is a function of rubber content in the mixtures such as 5,10 , and $15 \%$ given in the following equation:

$$
f\left(x_{\gamma}\right)=C_{1} \cdot\left(x^{2}\right)+C_{2} \cdot(x)+C_{3},
$$

where $C_{1}, C_{2}$, and $C_{3}$ are the constants and the values are presented in Table 3 considering the rubber types in the mixtures.

Based on the results of the tests shown in Figures 7-9, it was possible to adopt a relationship. Another aim of this work is to develop a practical method to evaluate the strain-dependent damping ratio as a function of the dynamic shear modulus ratio 

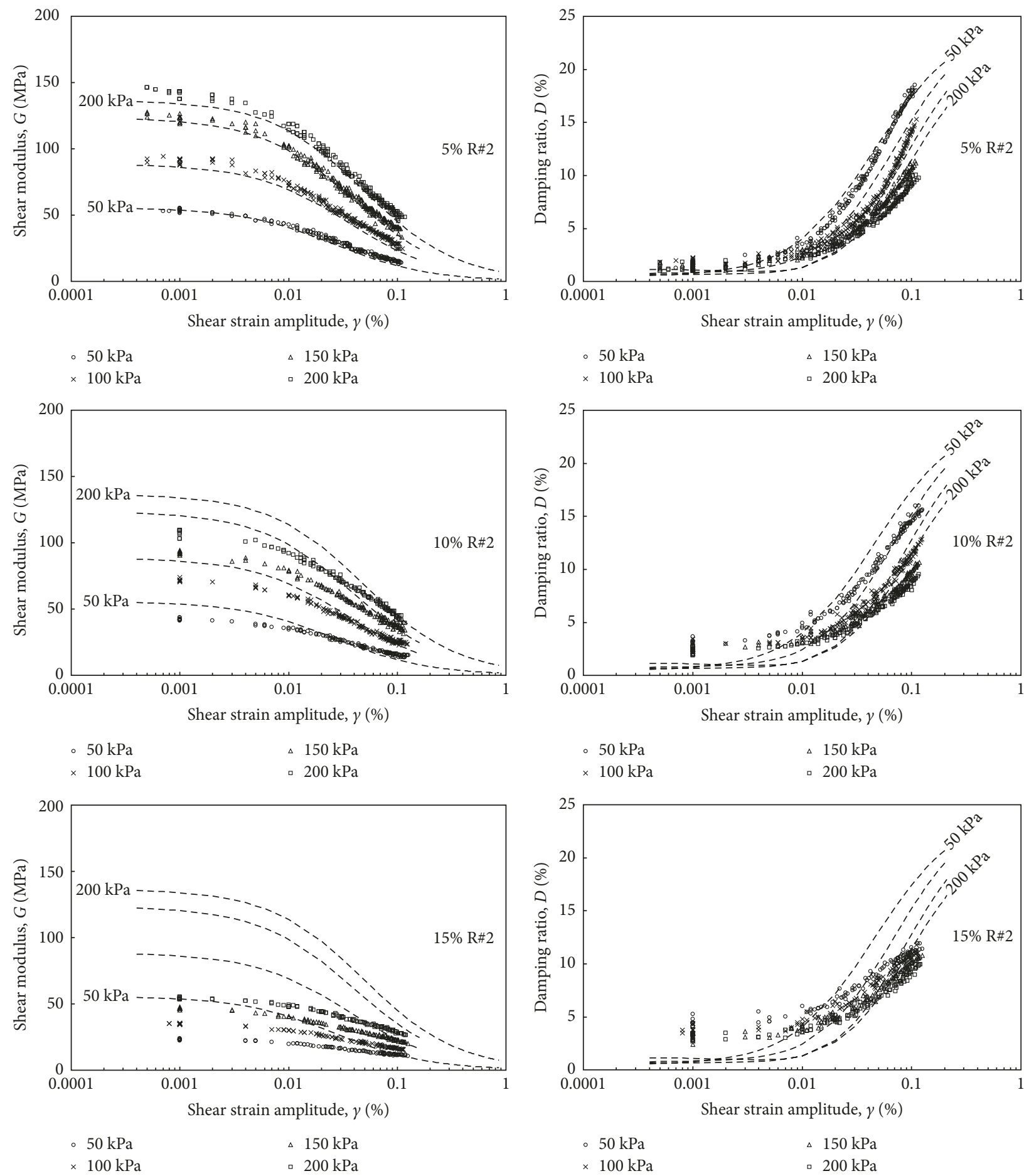

(a)
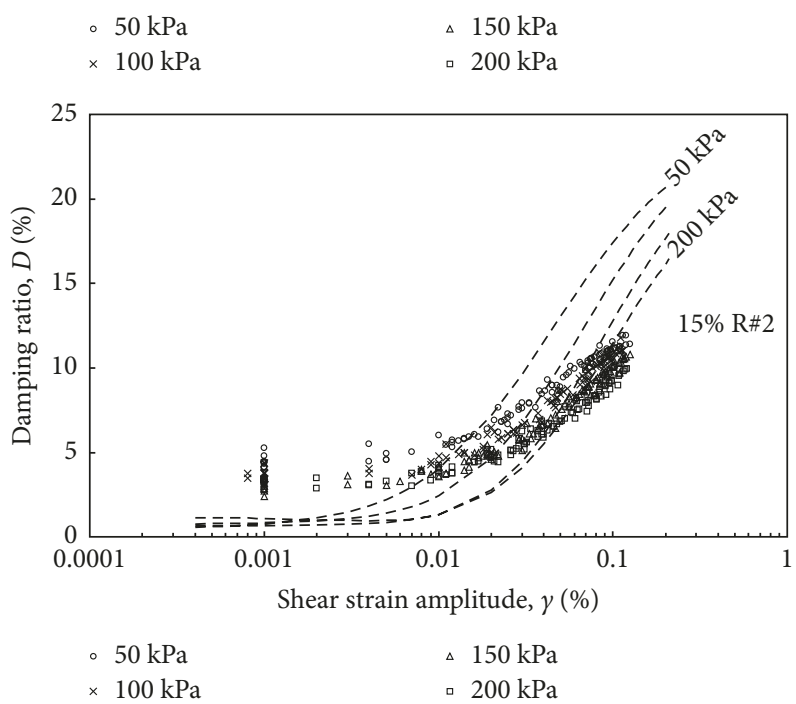

(b)

FIGURE 8: R\#2 sand mixture: (a) strain-dependent shear modulus and (b) strain-dependent damping ratio.

in a similar manner of [12]. As it is easier, less time-consuming, and less subjected to probable miscalculations, it may be needed to determine the damping ratio based on the dynamic shear modulus. On the basis of the model achieved by the equations, the results are presented with the test data in Figure 7 for R\#1. The recommended practical models for the shear modulus and damping ratio increase regarding the strain amplitude show reasonably good fit to the experimentally 

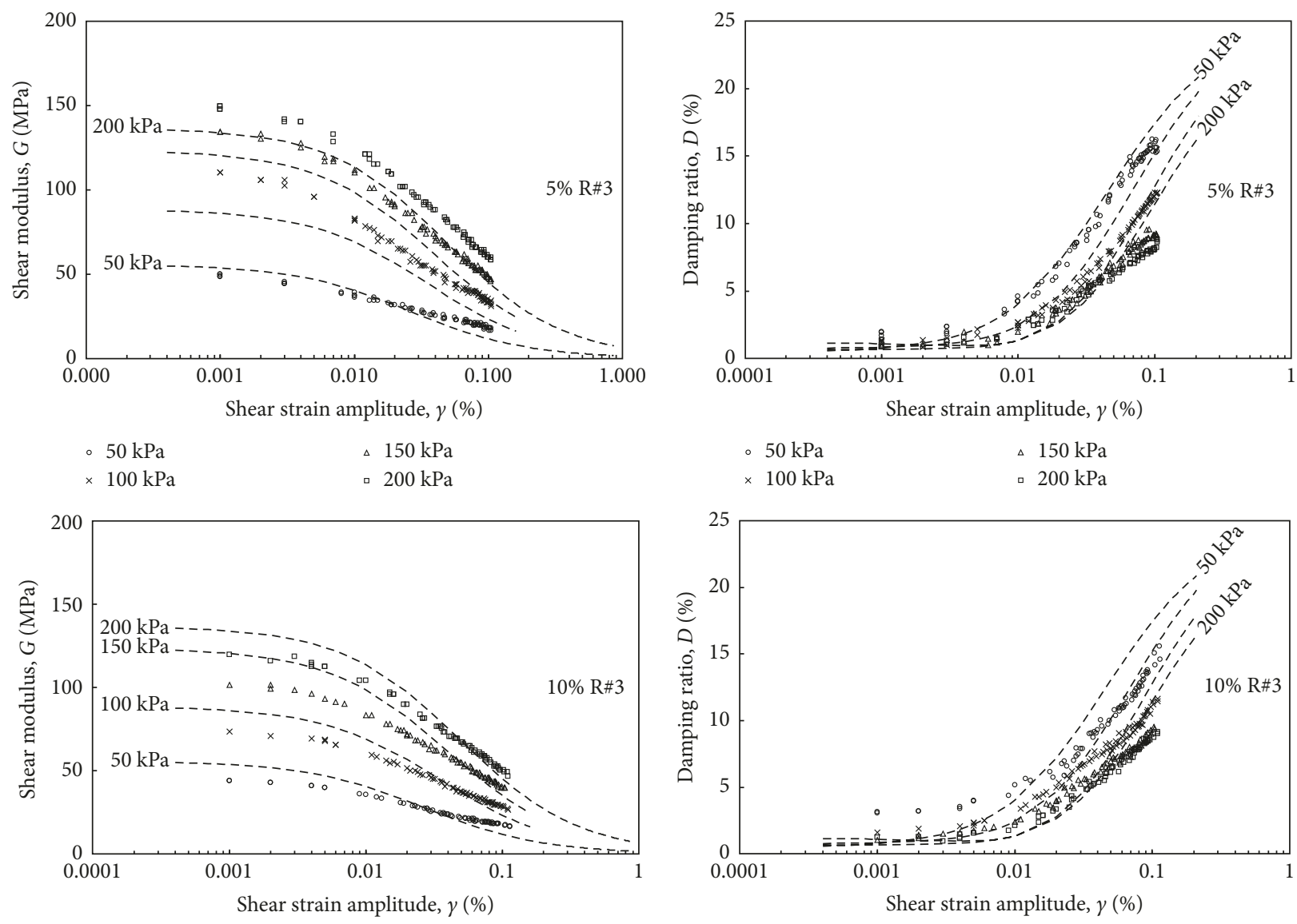

$\begin{array}{ll}\circ 50 \mathrm{kPa} & \triangle 150 \mathrm{kPa} \\ \times 100 \mathrm{kPa} & \text { 口 } 200 \mathrm{kPa}\end{array}$

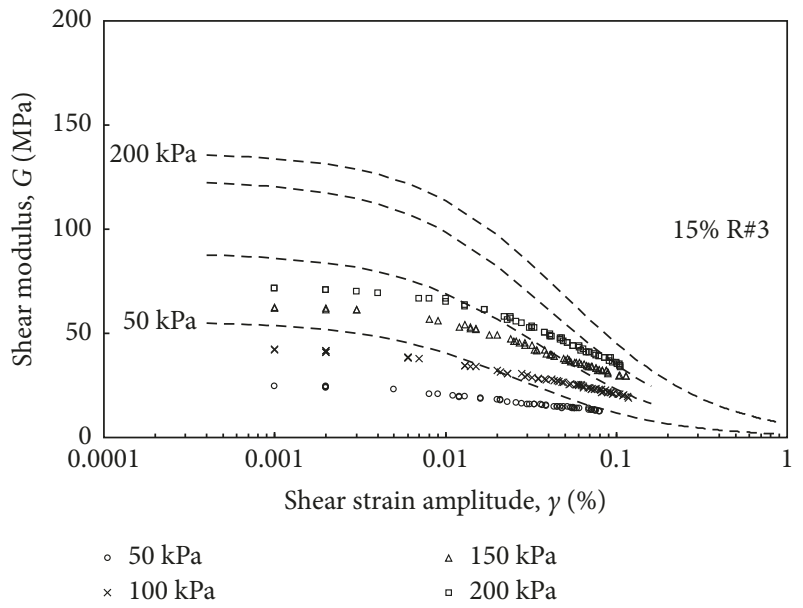

(a)

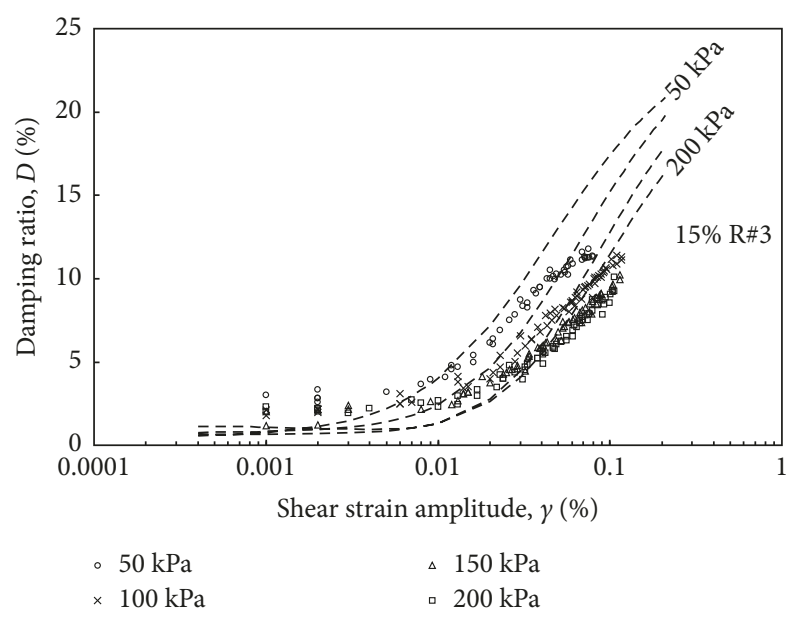

(b)

FIGURE 9: R\#3 sand mixture: (a) strain-dependent shear modulus and (b) strain-dependent damping ratio.

obtained results (Figures 10-12). For practical purposes, these relationships can be very useful, but for design purposes, tests are needed on case-specific materials.

\section{Conclusions}

The cyclic behavior of waste tire/sand mixtures was studied in detail based on a set of resonant column and cyclic torsional tests conducted on different mixture ratios. The purpose was to confirm the effecting parameters and to develop semiempirical relationships to determine the cyclic characteristics of rubber/sand mixtures. The maximum shear modulus, minimum damping ratio, strain dependency of shear modulus, and damping of rubber/sand material were evaluated under different cell pressures for different conditions of packing which were characterized by different 
TABle 2: $C_{1}, C_{2}$, and $C_{3}$ constants determined by the regression analysis.

\begin{tabular}{lccc}
\hline Material & $C_{1}$ & $C_{2}$ & $C_{3}$ \\
\hline $\mathrm{R} \# 1$ & 0.00167 & -0.01015 & 1.656 \\
$\mathrm{R} \# 2$ & 0.0083 & -0.06809 & 1.254 \\
$\mathrm{R} \# 3$ & 0.0078 & -0.01697 & 0.965 \\
\hline
\end{tabular}

TABLE 3: $A_{\gamma}$ and $n_{\gamma}$ constants determined by the regression analysis.

\begin{tabular}{lcc}
\hline Material & $A_{\gamma}$ & $n_{\gamma}$ \\
\hline $\mathrm{R} \# 1$ & 0.2235 & 0.3447 \\
$\mathrm{R} \# 2$ & 0.5654 & 0.1436 \\
$\mathrm{R} \# 3$ & 0.455 & 0.1856
\end{tabular}

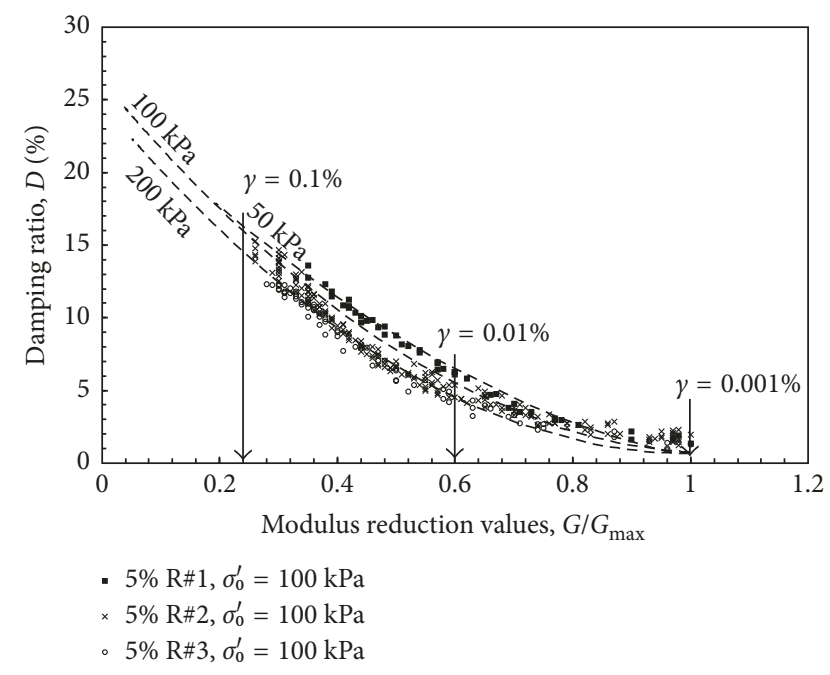

FIGURE 10: Relationship between shear modulus and damping ratio for $5 \%$ rubber content.

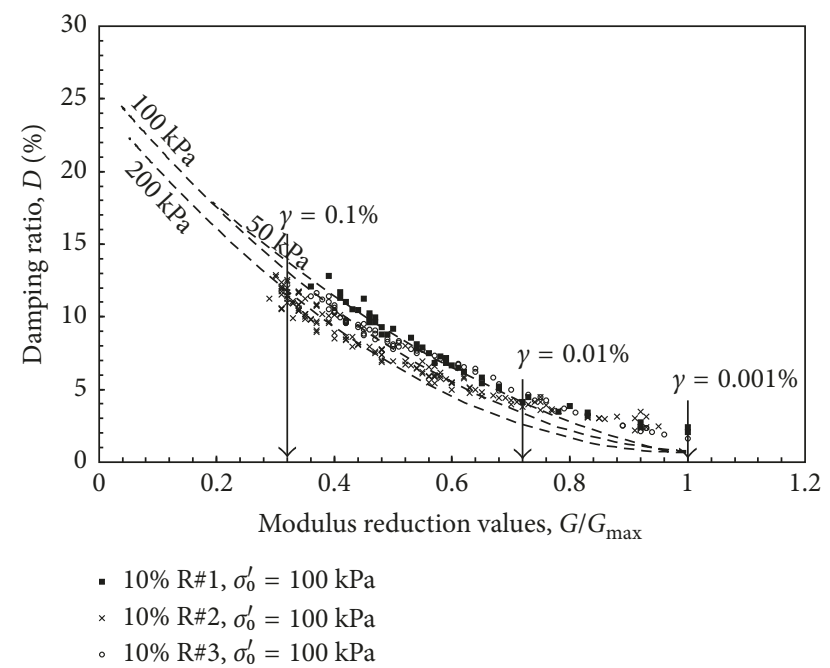

FIGURE 11: Relationship between shear modulus and damping ratio for $10 \%$ rubber content.

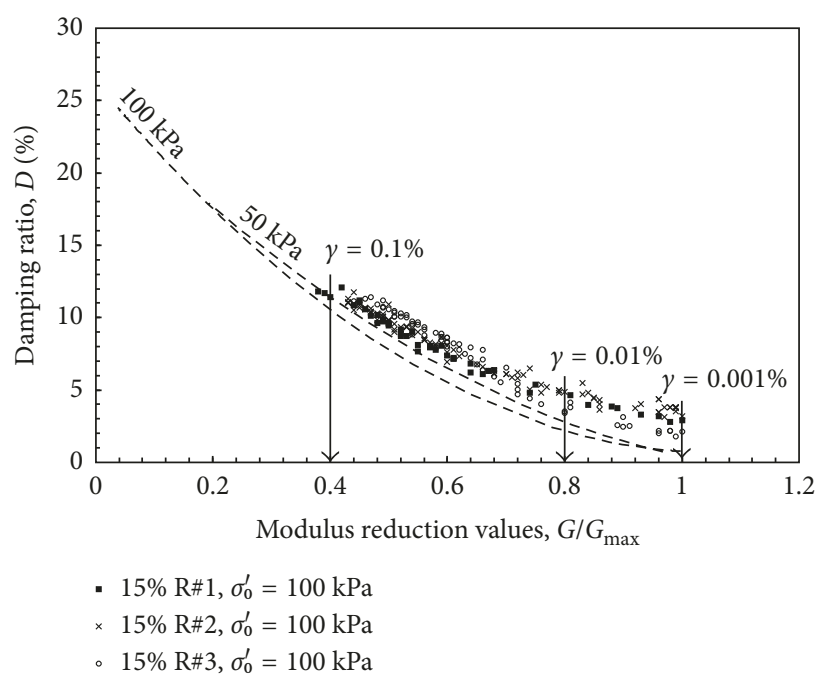

FIgURE 12: Relationship between shear modulus and damping ratio for $15 \%$ rubber content.

shapes and sizes of rubber. Unlike clean sand, rubber/sand mixtures have smaller values of shear modulus. This fact can be attributed to the decreasing of strength by the increasing amount of the rubber. From the results of these tests, it can be concluded that the mixtures with $5 \%$ rubber show almost the same cyclic stress-strain and damping behavior as clean sand. Additionally, the lower the confining stress, the higher the degree of similarity to the response of clean sand. The best fit was obtained from the confining stress of $50 \mathrm{kPa}$ and the R\#3 material, which was the finest in size. The degradation of the stiffness and increase in damping with decreasing confining stress are in agreement with the strain-dependent deformation characteristics of soils.

Despite the confining stresses varying between 50 and $200 \mathrm{kPa}$, there was almost no effect of the confining stress on the strain-dependent damping behavior of the mixtures with $10 \%$ and $15 \%$ rubber. This tendency is the opposite behavior of soil. In comparing the minimum damping ratio at a shear strain of $5 \times 10^{-4} \%$, the damping ratio increases with rubber content irrespective of rubber size.

\section{Conflicts of Interest}

The authors declare no conflicts of interest.

\section{Acknowledgments}

The authors would like to acknowledge the Eskişehir Osmangazi University, Scientific Research Project Unit, for the support of this work through Project no. 200915006.

\section{References}

[1] ASTM, "Standard practice for use of scrap tires in civil engineering applications, D6720-98," in Annual Book of ASTM Standards, ASTM International, West Conshohocken, PA, USA, 1998.

[2] U.S. Department of Transportation, August 2017, http://www. fhwa.dot.gov/pavement/pubs/hif14015.pdf. 
[3] T. B. Edil and P. J. Bossher, Development of Engineering Criteria for Shredded Waste Tires in Highway Applications, Research Report GT-92-9, Vol. 61, University of Wisconsin, Madison, WI, USA, 1992.

[4] D. N. Humphrey, Civil Engineering Applications of Tire Shreds, Report to California Integrated Waste Management Board, Vol. 15, California Environmental Protection Agency, Sacramento, CA, USA, 2003.

[5] T. B. Edil, J. K. Park, and J. Y. Kim, "Effectiveness of scrap tire chips as supportive drainage material," Journal of Environmental Engineering, vol. 130, no. 7, pp. 824-831, 2004.

[6] A. H. Aydilek, E. T. Madden, and M. M. Demirkan, "Field evaluation of a leachate collection system constructed with scrap tires," Journal of Geotechnical and Geoenvironmental Engineering, vol. 132, no. 8, pp. 990-1000, 2006.

[7] H. Hazarika, "Structural stability and flexibility during earthquakes using tyres (SAFETY) - a novel application for seismic disaster mitigation" in Proceedings of the International Workshop on Scrap Tire Derived Geomaterials -Opportunities and Challenges, H. Hazarika and T. Yasuhara, Eds., pp. 115125, Yokosuka, Japan, March 2007.

[8] M. Hyodo, S. Yamada, R. Orense, M. Okamoto, and H. Hazarika, "Undrained cyclic shear properties of tire chipsandmixtures," in Proceedings of the International Workshop on Scrap Tire Derived Geomaterials-Opportunities and Challenges, H. Hazarika and T. Yasuhara, Eds., pp. 187-196, Yokosuka, Japan, March 2007.

[9] K. Senetakis, A. Anastasiadis, K. Pitilakis, and A. Souli, "Dynamic behavior of sand/rubber mixtures, Part II: effect of rubber content on G/GO- $\gamma$-DT curves and volumetric threshold strain," Journal of ASTM International, vol. 9, no. 2, pp. 103711-1037112, 2012.

[10] K. Senetakis, A. Anastasiadis, K. Trevlopoulos, and K. Pitilakis, "Dynamic response of SDOF systems on soil replaced with sand/rubber mixture," in Proceedings of the ECOMAS Thematic Conference on Computation Methods in Structural Dynamics and Earthquake Engineering, Rhodes, Greece, June 2009.

[11] A. Anastasiadis, K. Senetakis, K. Pitilakis et al., "Dynamic behavior of sand/rubber mixtures, Part I: effect of rubber content and duration of confinement on small-strain shear modulus and damping ratio," Journal of ASTM International, vol. 9, no. 2, pp. 103680-1036819, 2012.

[12] K. Senetakis, A. Anastasiadis, and K. Pitilakis, "Dynamic properties of dry sand/rubber(SRM) and gravel/rubber (GRM) mixtures in a wide range of shearing strain amplitudes," Soil Dynamics and Earthquake Engineering, vol. 33, no. 1, pp. 38-53, 2012.

[13] A. Anastasiadis, K. Senetakis, and K. Pitilakis, "Small strain shear modulus and damping ratio of sand/rubber and gravel/ rubber mixtures," Geotechnical and Geological Engineering, vol. 30, no. 2, pp. 363-382, 2012.

[14] ASTM, "Standard test methods for specific gravity of soil solids by water pycnometer: D854-02," in Annual Book of ASTM Standards, ASTM International, West Conshohocken, PA, USA, 2002.

[15] H. J. Pincus, T. B. Edil, and P. J. Bosscher, "Engineering properties of tire chips and soil mixtures," Geotechnical Testing Journal, vol. 17, no. 4, pp. 453-464, 1994.

[16] J. Lee, R. Salgado, A. Bernal, and C. Lovell, "Shredded tires and rubber-sand as lightweight backfill," Journal of Geotechnical and Geoenvironmental Engineering, vol. 125, no. 2, pp. 132-141, 1999.
[17] R. C. Chaney, K. R. Demars, Z. Y. Feng, and K. G. Sutter, "Dynamic properties of granulated rubber/sand mixtures," Geotechnical Testing Journal, vol. 23, no. 3, pp. 338-344, 2000.

[18] J. P. Mulilis, H. B. Seed, C. K. Chan, J. K. Mitchell, and K. Arulanandan, "Effects of sample preparation on sand liquefaction," Journal of Geotechnical Engineering Division, vol. 103, no. 2, pp. 91-108, 1977.

[19] V. P. Drnevich, "Recent developments in resonant column testing," in Proceedings of the Richart Commemorative Lectures, ASCE Annual Meeting, Specialty Session, pp. 79 -107, Detroit, MI, USA, 1985.

[20] ASTM D4015, Standard Test Methods for Modulus and Damping of Soils by Resonant Column Method, ASTM International, West Conshohocken, PA, USA, 2007.

[21] S. Youwai and D. T. Bergado, "Strength and deformation characteristics of shredded rubber tire sand mixtures," $\mathrm{Ca}$ nadian Geotechnical Journal, vol. 40, no. 2, pp. 254-264, 2011.

[22] K. Ishihara, Soil Behavior in Earthquake Geotechnics, Clarendon Press, Oxford, UK, 1996.

[23] T. Kokusho, "Cyclic triaxial test of dynamic soil properties for wide strain range," Soils and Foundations, vol. 20, no. 2, pp. 45-60, 1980.

[24] B. O. Hardin and V. P. Drnevich, "Shear modulus and damping in soil: design equations and curves," Journal of the Soil Mechanics and Foundations Division, vol. 98, no. 7, pp. 667-692, 1972. 


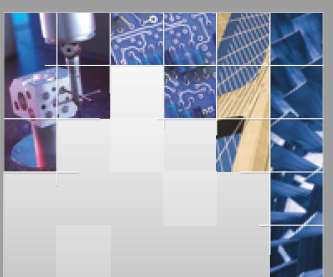

\section{Enfincering}
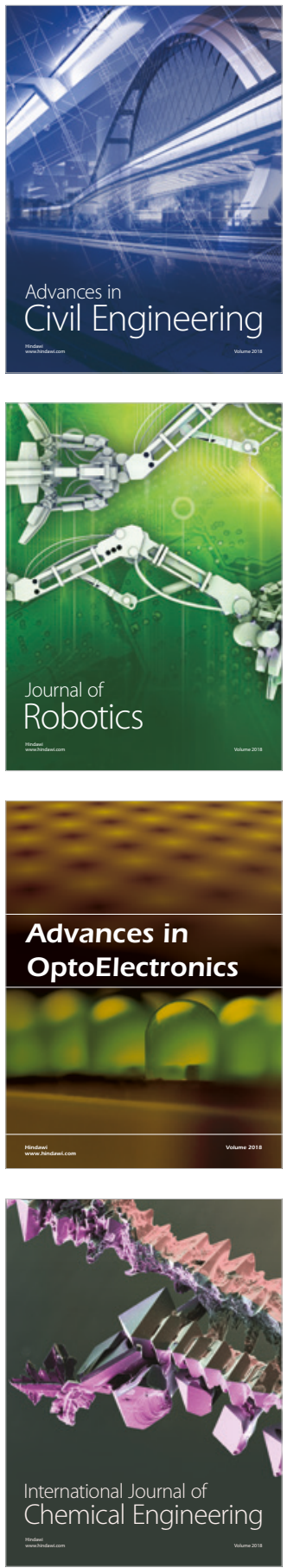

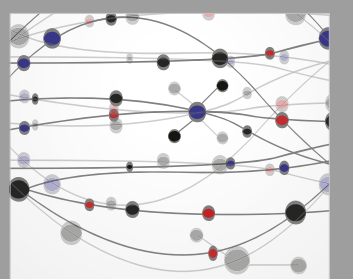

\section{Rotating \\ Machinery}

The Scientific World Journal

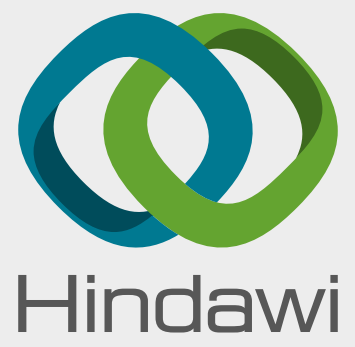

Submit your manuscripts at

www.hindawi.com
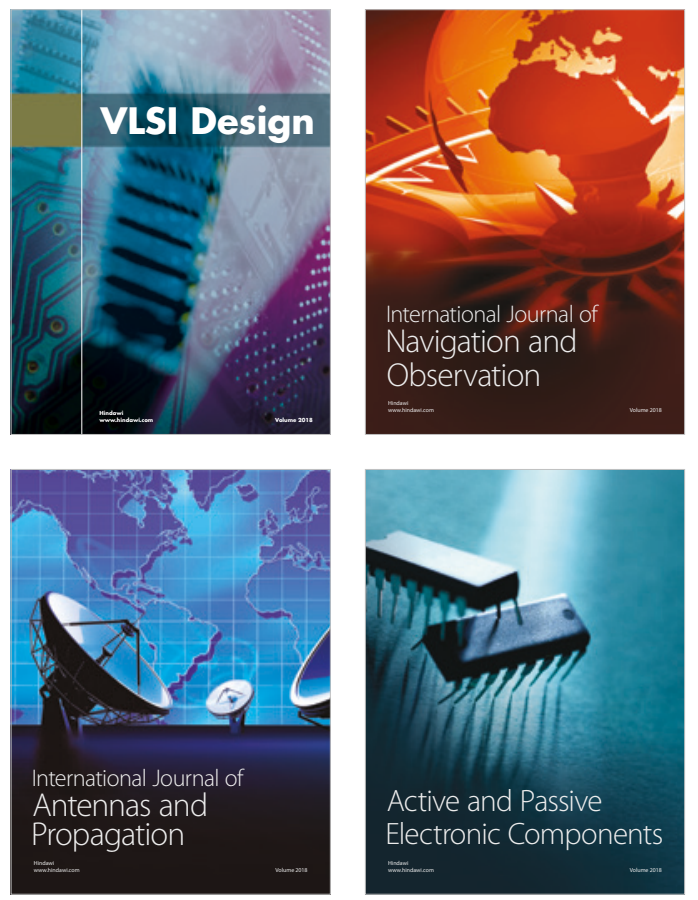
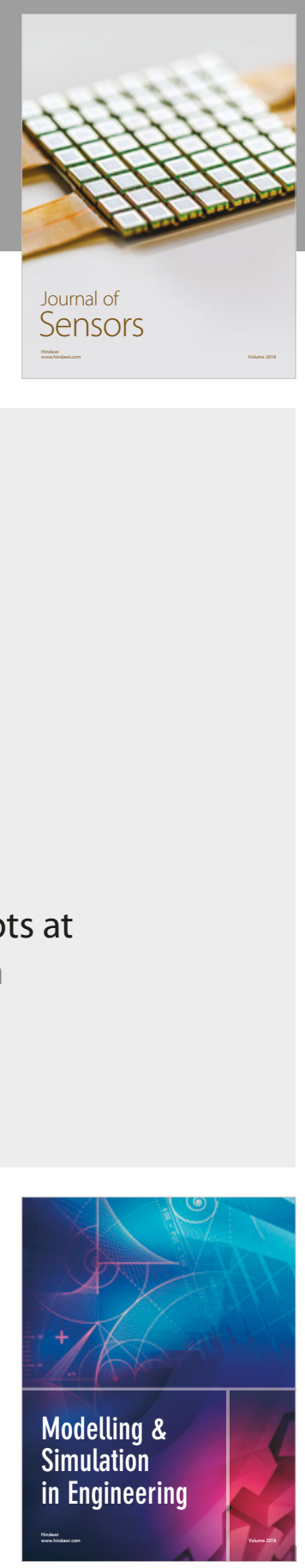

\section{Advances \\ Multimedia}
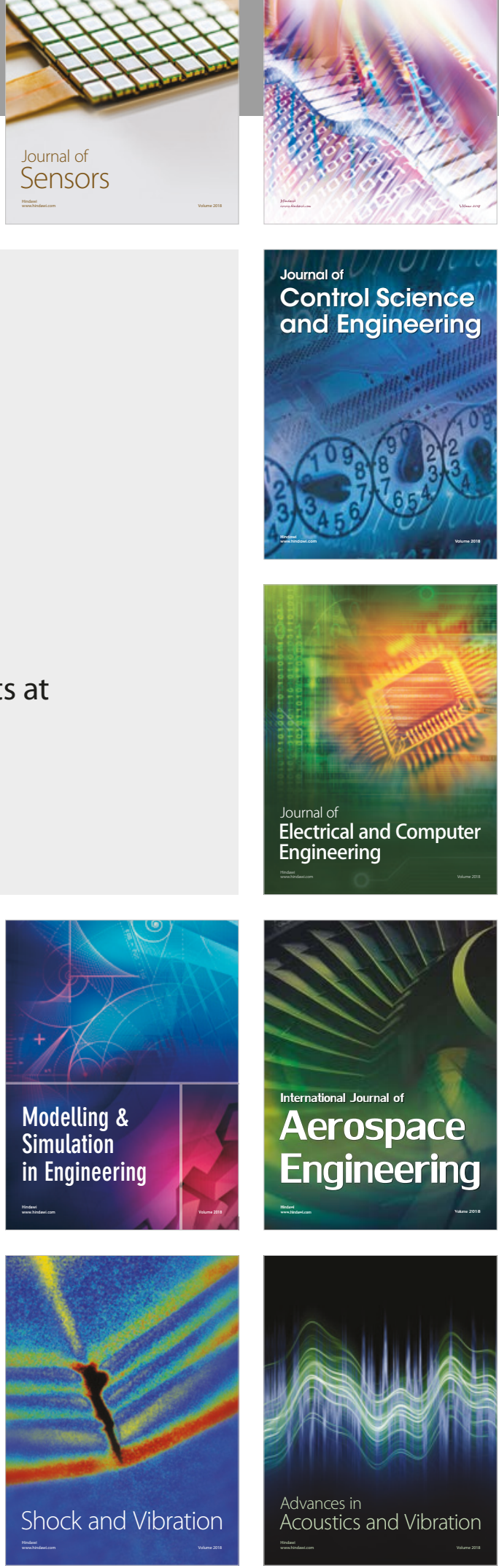